\title{
COVID-19: Comparison of immunogenicity response between \\ natural and post-vaccination infections [version 1; peer
}

\section{review: 1 approved]}

\author{
Ivonne Elisabeth Rotty ${ }^{1}$, Erwin Kristanto (11,2, Sekplin Sekeon1,2, \\ Henny Ruth Liwe ${ }^{1}$, Neni Ekawardani ${ }^{1}$
}

${ }^{1}$ RSUP Prof. Dr. RD. Kandou, Sam Ratulangi University, Manado, North Sulawesi, 95115, Indonesia

${ }^{2}$ Faculty of Medicine/RSUP Prof. Dr. RD. Kandou, Sam Ratulangi University, Manado, North Sulawesi, 95115, Indonesia

V1 First published: 22 Feb 2022, 11:212
https://doi.org/10.12688/f1000research.75537.1

Latest published: 22 Feb 2022, 11:212

https://doi.org/10.12688/f1000research.75537.1

\section{Abstract}

Background: The COVID-19 pandemic in Indonesia has been ongoing for a year as at time of writing, since March 2020. Vaccination interventions are public health efforts that are arguably the most effective in the current pandemic situation, in addition to routine health protocols. Until now, there have been few reports of the effectiveness of vaccination and antibody titers formed after vaccination is carried out. This study aims to find out the difference in antibody titers after vaccination in confirmed COVID-19 cases.

Methods: This observational study investigated the difference in SARS-Cov-2 quantitative antibody titers between two cohorts: unvaccinated COVID patients who were confirmed -with COVID-19 and individuals undergoing vaccination at the hospital Prof. dr. R. D. Kandou Manado. Inclusion and exclusion criteria, statistical analysis, and research ethics were applied in the study.

Results: Antibody titers in survivor groups were relatively lower at 56 days and 84 days after COVID-19 diagnosis, while the antibody titer in the elderly group undergoing vaccination relatively increased at 56 days and 84 days after the first vaccination. There was a significant difference in antibody titers between a group of survivors and those who underwent vaccination on the first (28 days) and third ( 84 days). Conclusions: From this study, it was found that in the naturally COVID-19-infected group, antibody titers were still found for 84 days after COVID-19 diagnosis. In the group undergoing vaccination, it was found that antibody titers increased significantly at 56 days after vaccination.

Keywords

COVID-19, Immune response, Survivor, Vaccination, Antibody Titer

\section{Open Peer Review \\ Approval Status \\ 1 \\ version 1 \\ 22 Feb 2022 \\ view \\ 1. Anggraini Dwi Sensusiati (iD), Universitas \\ Airlangga Hospital, Surabaya, Indonesia \\ Any reports and responses or comments on the article can be found at the end of the article.}




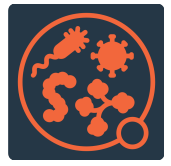

This article is included in the Pathogens

gateway.

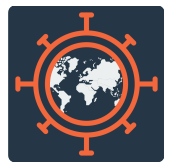

This article is included in the Emerging Diseases

and Outbreaks gateway.

Corresponding authors: Ivonne Elisabeth Rotty (drivonnerotty@gmail.com), Erwin Kristanto (kristantogidion@gmail.com), Neni Ekawardani (neniekawardani254@gmail.com)

Author roles: Rotty IE: Conceptualization, Formal Analysis, Funding Acquisition, Investigation, Supervision, Writing - Original Draft Preparation, Writing - Review \& Editing; Kristanto E: Conceptualization, Data Curation, Formal Analysis, Investigation, Writing - Original Draft Preparation, Writing - Review \& Editing; Sekeon S: Formal Analysis, Project Administration, Writing - Review \& Editing; Liwe HR: Formal Analysis, Writing - Original Draft Preparation, Writing - Review \& Editing; Ekawardani N: Supervision, Validation, Writing Review \& Editing

Competing interests: No competing interests were disclosed.

Grant information: This study was supported by RSUP Prof.dr.R.D Kandou (HK.02.03/XIX.3/1186.1/2021).

The funders had no role in study design, data collection and analysis, decision to publish, or preparation of the manuscript.

Copyright: ( $) 2022$ Rotty IE et al. This is an open access article distributed under the terms of the Creative Commons Attribution License, which permits unrestricted use, distribution, and reproduction in any medium, provided the original work is properly cited.

How to cite this article: Rotty IE, Kristanto $E$, Sekeon $S$ et al. COVID-19: Comparison of immunogenicity response between natural and post-vaccination infections [version 1; peer review: 1 approved] F1000Research 2022, 11:212

https://doi.org/10.12688/f1000research.75537.1

First published: 22 Feb 2022, 11:212 https://doi.org/10.12688/f1000research.75537.1 


\section{Introduction}

The COVID-19 pandemic in Indonesia has been running for a year since March 2020. Severe acute respiratory syndrome coronavirus 2 (SARS-Cov-2) can cause respiratory failure and even multiple organ failure (Pal et al., 2020). Vaccination efforts are needed to prevent the burden of pandemics in the form of increased morbidity and mortality, and to reduce the rate of transmission of the SARS-Cov-2 virus. ${ }^{1}$

Vaccination interventions are arguably the most effective public health efforts in the current pandemic situation, in addition to routine health protocols (Dinleyici et al., 2021). ${ }^{2}$ The vaccine can protect individuals against SARS-Cov-2 infection, as well as suppress the severity of the COVID-19 disease (Pascual-Igleas et al., 2021). However, no vaccine provides $100 \%$ total protection. ${ }^{3}$ After vaccination, information is needed about the proportion of communities that have had an immune response after the vaccination program. Thus, the evaluation of antibodies produced after vaccination is necessary.

Research to find humoral responses in adults aged 60 years and older was conducted by Zhiwei Wu et al. in $2020 .{ }^{4}$ The study was carried out on 72 respondents with placebo and CoronaVac vaccination interventions in two separate groups and was carried out in two phases with a time interval of 28 days. The results of this study showed that CoronaVac is well tolerated and induces a humoral response in adults aged 60 years and older, which supports the use of this vaccine in older populations.

Until now, there are still few reports of the effectiveness of vaccination and antibody titers formed after vaccination is carried out. Furthermore, not many publications have reported differences in antibody production after vaccination compared to the antibody titers of unvaccinated, recovered COVID-19 patients. Furthermore, it is necessary to know the difference in the duration of the formation of natural post-infectious antibodies and post-vaccination. Therefore, this study aimed to find out the difference in antibody titers after vaccination, in individuals with confirmed COVID-19.

\section{Methods}

Study design

The type of study conducted was a cohort observation, investigating the difference in SARS-Cov-2 quantitative antibody titers between patients who were confirmed, unvaccinated COVID-19 cases, and individuals who underwent vaccination at the hospital Prof. dr. R. D. Kandou Manado. The study was conducted at the Prof. dr. R. D. Kandou Hospital from March to August 2021.

\section{Population}

The study population was confirmed, unvaccinated of COVID-19 patients treated in the COVID-19 infectious treatment room of Prof. dr. R. D. Kandou Hospital and individuals who underwent vaccinations at Prof. dr. R. D. Kandou Hospital.

\section{Sample}

This study consisted of two groups, naturally infected COVID-19 patient and individual who underwent vaccination, with a sample size of 30 for each group. The study subjects were samples that met the inclusion criteria described below.

\section{Operational definitions}

- SARS-Cov-2 quantitative antibody titer: The results of the measurement of specific antibodies with the Electro Chemiluminescence Immunoassay (ECLIA) method, using recombinant proteins representing the receptor binding domain (RBD) of the SARS-CoV-2 spike (S) protein in the serum of patients, measured as U/ml units ( $1 \mathrm{U} / \mathrm{ml}$ equivalent to $0.972 \mathrm{BAU} / \mathrm{ml}$ of international standard units from $\mathrm{WHO}$ ).

In this study, we obtained antibody titer results using the ArchitectPlus i1000SR tool made by Abbot, USA with three types of reagents used, namely:

a. SARS Cov-2 immunoglobulin G (IgG) antibody reagent with catalogue number 28453FN00.

b. Sars Cov-2 IgG antibody reagent control with catalogue number 3056FN00.

c. Sars Cov-2 IgG calibration antibody reagent with catalogue number 29156FN00.

- SARS-Cov-2 survivor: People who survived infection with COVID-19, or people who recovered from COVID-19. 
- Individuals undergoing vaccination: Individuals receiving an injection of the COVID-19 vaccine.

- Confirmed patients with SARS-Cov-2: People who have tested positive for the coronavirus based on the results of laboratory examinations.

\section{Inclusion criteria}

- Aged 18 years or older.

- Willing to participate in the research.

- Confirmed COVID-19 patients, i.e., confirmed COVID-19 cases treated in infectious treatment rooms or in the outpatient COVID-19 polyclinic at RSUP Prof. dr. R. D. Kandou Hospital.

- Individuals have undergone SARS-Cov-2 vaccination at Prof. dr. R. D. Kandou Hospital.

- Willing to be contacted to conduct further checks.

\section{Exclusion criteria}

- Individuals who did not continue or did not get a second vaccination.

- Survivors who have been vaccinated.

- Confirmed COVID-19 patients who died in treatment.

- Subjects who dropped out in the course of the study.

\section{Study procedure}

Confirmed COVID-19 patients treated as confirmed COVID-19 cases and individuals undergoing vaccination were included in the study after passing the selection criteria. Most of the participants belonged to the non-elderly age group, so this group was further divided into two more groups, those with comorbid and without comorbid, with the same number of samples as elderly respondents. Sampling was carried out with a simple stratified random sampling technique for each group.

After a period of 28, 56, and 84 days (test 1, 2 and 3 respectively) after the diagnosis of COVID-19 for confirmed COVID19 patients, a blood sample examination was carried out to measure SARS-CoV-2 antibody titer levels. Quantitative AntiCov-2 examination is a test that measures quantitative in vitro levels of antibodies (including IgG) specific to the RBD of the SARS-CoV-2 S protein; it aims to assess the adaptive humoral immune response to the SARS-CoV-2 S protein.

The same measurement was done for individuals who underwent SARS-Cov-2 vaccination.

Comparison of SARS-Cov-2 antibody titer levels was conducted between the group of unvaccinated patients with confirmed COVID-19 and individuals undergoing vaccination.

Secondary data (demographic characteristics) such as age, sex, elderly status, and infection status were taken from the patient's medical record.

Statistical analysis

A descriptive analysis was carried out on the demographic and clinical criteria of the research subject.

Bivariate analysis with an independent T-test (if data distribution was normal) or was carried out with Mann-Whitney $\mathrm{U}$ test (if the data were not normally distributed) was carried out to determine the difference in the average antibody titers between the two groups. Furthermore, to assess the difference in antibody levels in all three tests for each group of study subjects, the Friedman two-way ANOVA by rank test followed by post hoc analysis with the Bonferroni method were used.

The analysis was conducted with a significance level of 5\% using SPSS version 20 software. 
Study ethics

The research protocol was reviewed according to the standards of the Council of International Organizations of Medical Sciences (CIOMS).

The subject of the study was related to the principle of good clinical practice.

Ethical clearance was submitted to the Health Research Ethics Committee of RSUP Prof. dr. R. D. Kandou and was issued with Number 041/KEPK-KANDOU/III/2021 The research was submitted to the President Director of RSUP Prof. dr. R.D. Kandou Manado. All subjects or participants whose data are listed in the paper have agreed by signing the Informed Consent.

\section{Results}

Of the total sample constituted of 65 people, nine subjects had incomplete results (i.e., died or discontinued participation to the study) and were therefore excluded from the analysis. The distribution of the study subjects' demographic characteristics can be seen in Table 1, where the subjects are classified by age group, elderly status, sex, and vaccination status.

Based on demographic characteristics data in study subjects, it was found that most belonged to the non-elderly age group. Female gender made up the majority with $60.7 \%$. The proportions were balanced between the group of survivors and vaccinations. Table 2 shows that $37.5 \%$ of the subjects who participated in this study were in the elderly group and $62.5 \%$ of the subjects were in the non-elderly age group.

From the results of the cross-table analysis above, it was found that there was a relatively balanced composition between the group of survivors and vaccinations in both the elderly and non-elderly categories.

A bivariate analysis was conducted to see differences in antibody levels in the elderly and non-elderly groups, followed by an other analysis to see the difference between the status of survivors and vaccinations in each age group, both elderly and non-elderly.

Table 1. Distribution of demographic characteristics.

\begin{tabular}{|l|l|l|l|}
\hline Variable & Group & $\mathbf{n}$ & \% \\
\hline Age Group & $61+$ & 18 & 32.1 \\
\hline & $51-60$ & 12 & 21.4 \\
\hline & $41-50$ & 13 & 23.2 \\
\hline & $31-40$ & 8 & 14.3 \\
\hline Elderly & $21-30$ & 5 & 8.9 \\
\hline Sex & Yes & 21 & 37.5 \\
\hline Status & No & 35 & 62.5 \\
\hline Total & Female & 34 & 60.7 \\
\hline & Male & 22 & 39.3 \\
\hline & Survivor & 28 & 50.0 \\
\hline & Vaccinated & 28 & 50.0 \\
\hline & & 56 & 100.0 \\
\hline
\end{tabular}

Table 2. Cross tabulation data.

\begin{tabular}{|l|l|l|l|l|l|l|}
\hline Group & Survivor & \multicolumn{3}{|l}{ Vaccinated } & Total \\
\hline & $\mathbf{n}$ & $\mathbf{\%}$ & $\mathbf{n}$ & \% & $\mathbf{n}$ & \% \\
\hline Elderly & 10 & 17.9 & 11 & 19.6 & 21 & 37.5 \\
\hline Non-elderly & 18 & 32.1 & 17 & 30.4 & 35 & 62.5 \\
\hline Total & 28 & 50.0 & 28 & 50.0 & 56 & 100 \\
\hline
\end{tabular}


Based on the results of the distribution of antibody levels in the form of median values in the elderly group (Figure 1), it was observed that antibody levels in the elderly survivor group were decreased, which appeared to be a $50 \%$ reduction in the median value between the first and last test. In contrast, in the elderly group who underwent vaccination, there was a widening of the interquartile range comprising $50 \%$ of the values around the median for test 1 to test 3 .

When the Mann-Whitney U test was conducted to see the difference in antibody levels of each group in each test, it was found that there was a statistically significant difference in the results of test 1 (Table 3).

In the non-elderly group without comorbidities, the distribution of median values showed a decrease (Figure 2), as shown by lower median scores for tests 2 and 3 compared to tests 1 . On the other hand, there was an increase in median scores in the vaccination group, coinciding with a widened interquartile range for values from tests 2 and 3 ; these values were higher and had a wider distribution compared to test 1 (Figure 2).

Based on the calculation results from the Mann-Whitney U test, there was a statistically significant difference in both of the non-elderly survivors without comorbidities and those in the vaccinated group (Table 4).

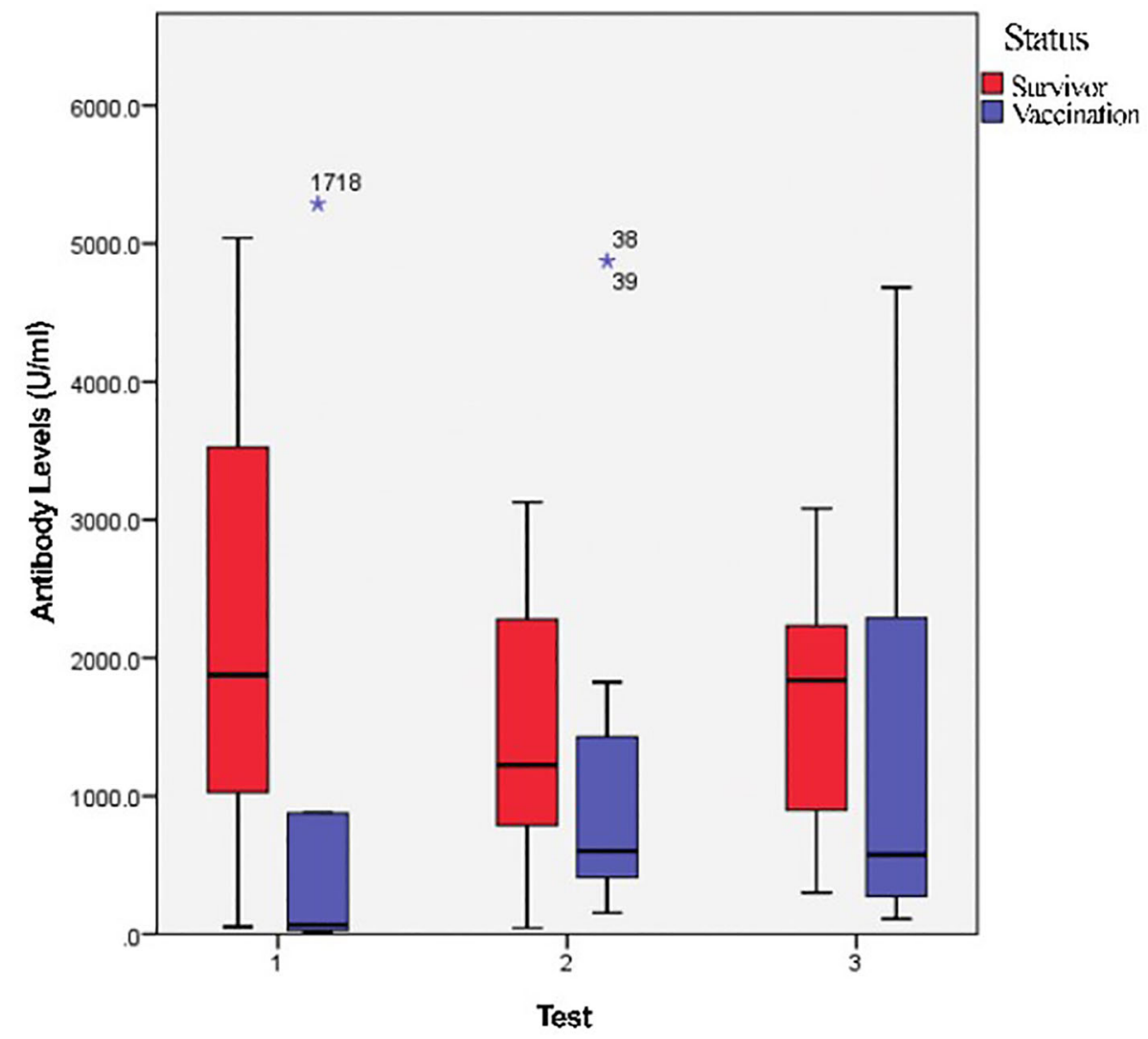

Figure 1. Distribution of antibody yield values in older patients.

Table 3. Spread of antibody levels in the elderly group.

\begin{tabular}{|l|l|l|l|l|}
\hline Test & Status & $\mathbf{n}$ & Mean Mann-Whitney U rank & $\mathbf{p}$-value \\
\hline Test 1 & Survivor & 10 & 13.9 & 0.04 \\
\cline { 2 - 5 } & Vaccinated & 11 & 8.3 & 0.43 \\
\hline \multirow{2}{*}{ Test 2 } & Survivor & 10 & 12.1 & 10.0 \\
\hline \multirow{2}{*}{ Test 3 } & Vaccinated & 11 & 12.9 & 0.18 \\
\hline
\end{tabular}




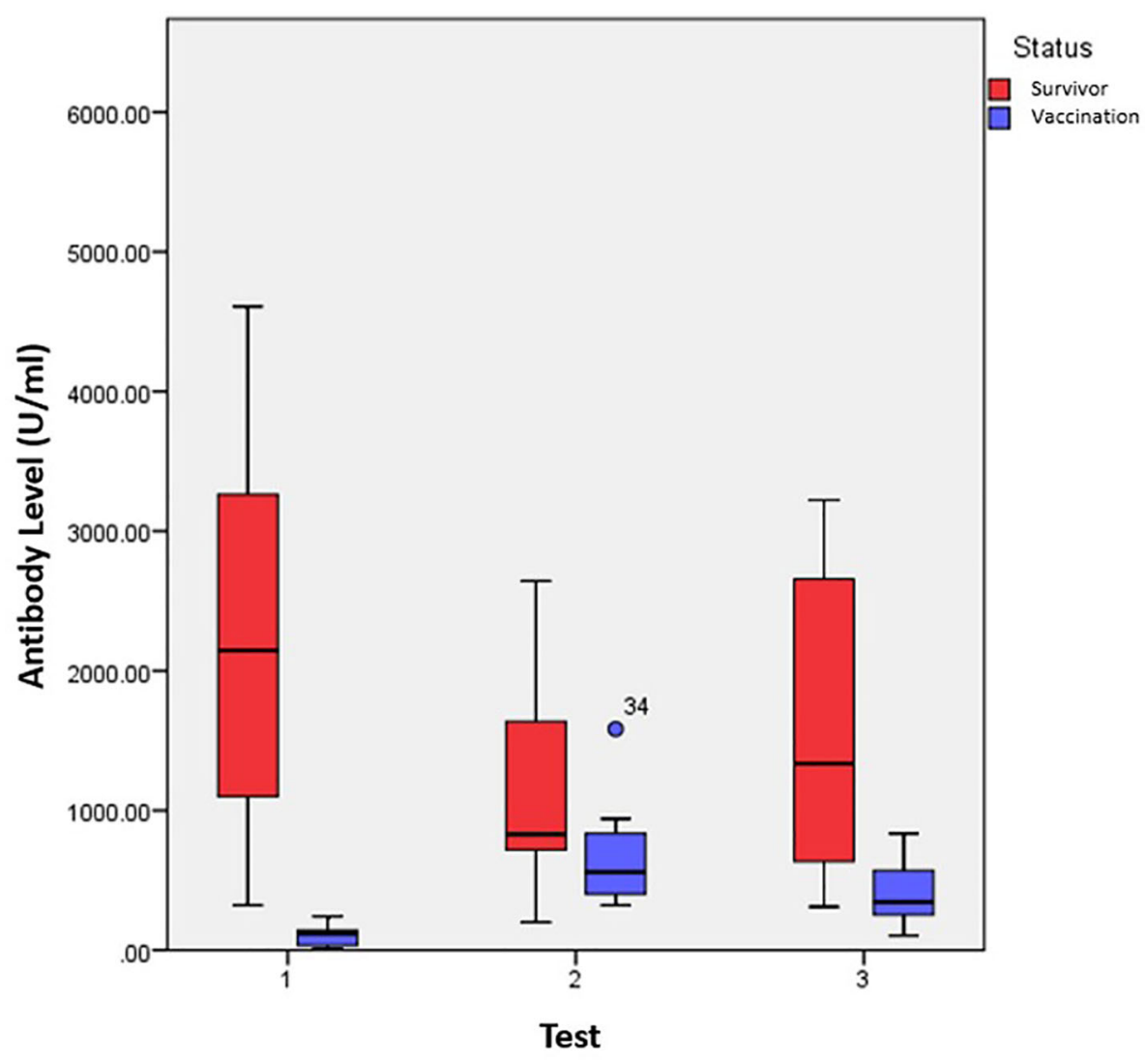

Figure 2. Distribution of antibody yield values in non-comorbid, non-elderly patients.

Table 4. Spread of antibody levels in non-comorbid non-elderly groups.

\begin{tabular}{|l|l|l|l|l|}
\hline Test & Status & $\mathbf{n}$ & Mean Mann-Whitney U rank & p-value \\
\hline Test 1 & Survivor & 9 & 13.5 & 0.00 \\
\cline { 2 - 4 } & Vaccinated & 9 & 5.4 & 0.20 \\
\hline \multirow{2}{*}{ Test 2} & Survivor & 9 & 11.1 & 0.01 \\
\hline \multirow{2}{*}{ Test 3 } & Vaccinated & 9 & 7.8 & \\
\hline
\end{tabular}

The spread of antibody levels in non-elderly groups with comorbidities showed a decrease in median values for survivors. However, the pattern was also relatively similar for the group that underwent vaccinations. Visually, there was also a reduction in the spread of the interquartile range for both groups (Figure 3).

The visual patterns described above were confirmed by the absence of significant differences between the groups of survivors and vaccinated patients, based on the results of the Mann-Whitney U test (Table 5).

When sorting the total sample according to survivor and vaccination status, ignoring the age group variable, a decrease in the median value in the survivor group appeared. There was also a decrease in the median scores of tests 2 and 3 compared to tests 1 (Figure 4). On the contrary, there was an increase in the median score in the vaccination group, with higher values for tests 2 and 3 than that of test 1 . 


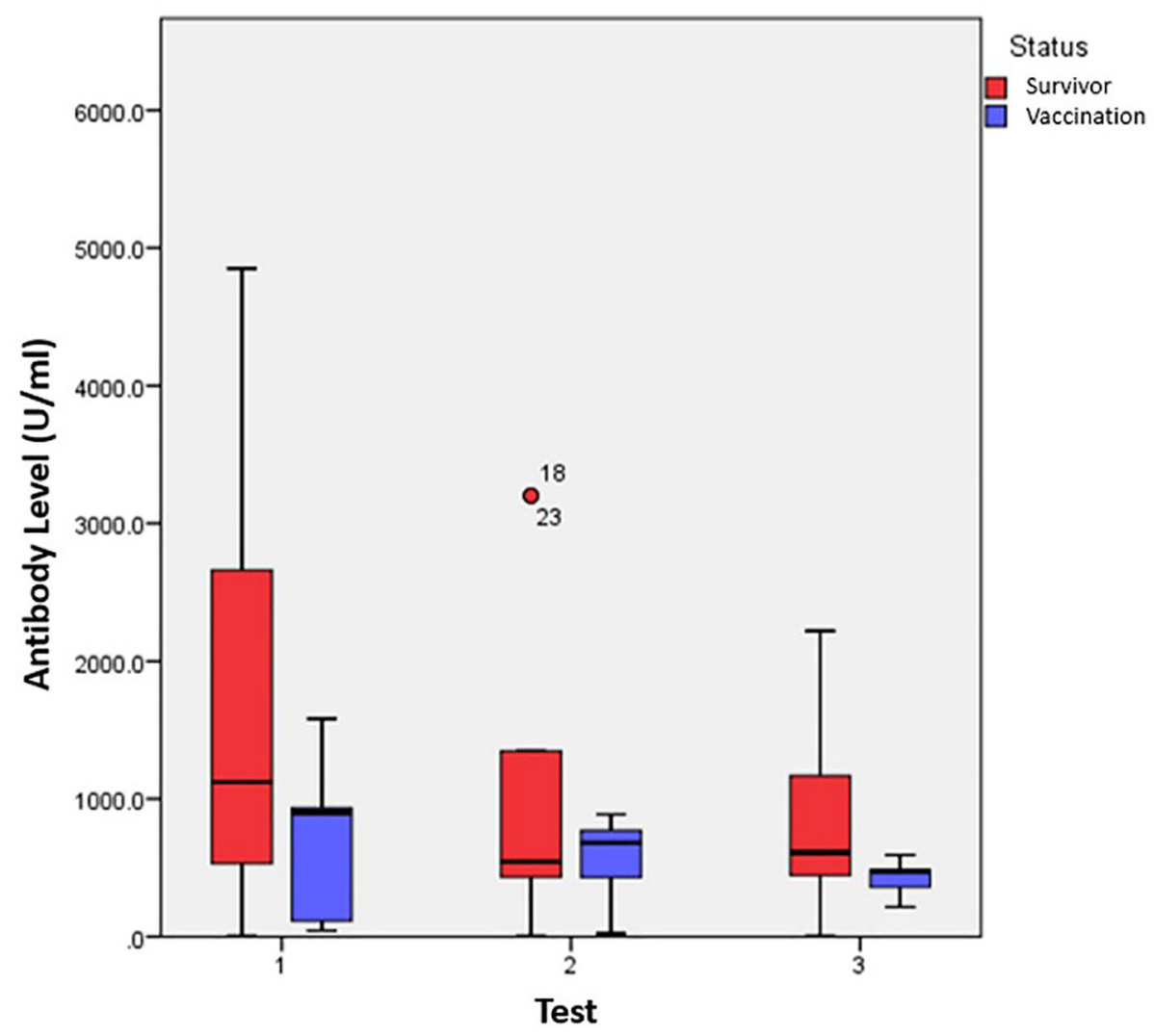

Figure 3. Distribution of antibody yield values in non-comorbid senior (elderly) citizens.

Table 5. Spread of antibody levels in non-comorbid, non-elderly groups.

\begin{tabular}{|l|l|l|l|l|}
\hline Test & Status & $\mathbf{n}$ & Mean Mann-Whitney U rank & p-value \\
\hline Test 1 & Survivor & 9 & 9.8 & 0.18 \\
\cline { 2 - 5 } & Vaccinated & 7 & 6.7 & 0.95 \\
\hline \multirow{2}{*}{ Test 2 } & Survivor & 9 & 8.5 & 0.63 \\
\hline & Vaccinated & 7 & 8.4 & \\
\hline \multirow{2}{*}{ Test 3 } & Survivor & 9 & 9.0 & \\
\cline { 2 - 5 } & Vaccinated & 7 & 7.8 & \\
\hline
\end{tabular}

There was a significant difference in the median antibody levels of the survivors' group and that of vaccinated subjects between tests 1 and 3. This is likely due to changes in median levels in both.

Furthermore, to assess the difference in antibody levels in all three tests for each group of study subjects, the Friedman two-way ANOVA by rank test followed by post hoc analysis with the Bonferroni method were used. The goal was to analyze the differences in each test, and if there were differences, to determine which tests had significantly different values (Table 7).

The results of the analysis with the Friedman test above showed statistical differences in antibody levels in all three tests conducted, for all categories except in young age groups with comorbidities and not vaccinated $\left(\mathrm{x}^{2}=2.00, \mathrm{p}=0.37\right)$.

\section{Discussion}

In this study, the majority of subjects belonged to the age group over 60 years, with a proportion of $32.1 \%$, followed by the age group 41-50 years (23.2\%) and 51-60 years (21.4\%). However, in general, the young age group composition still 


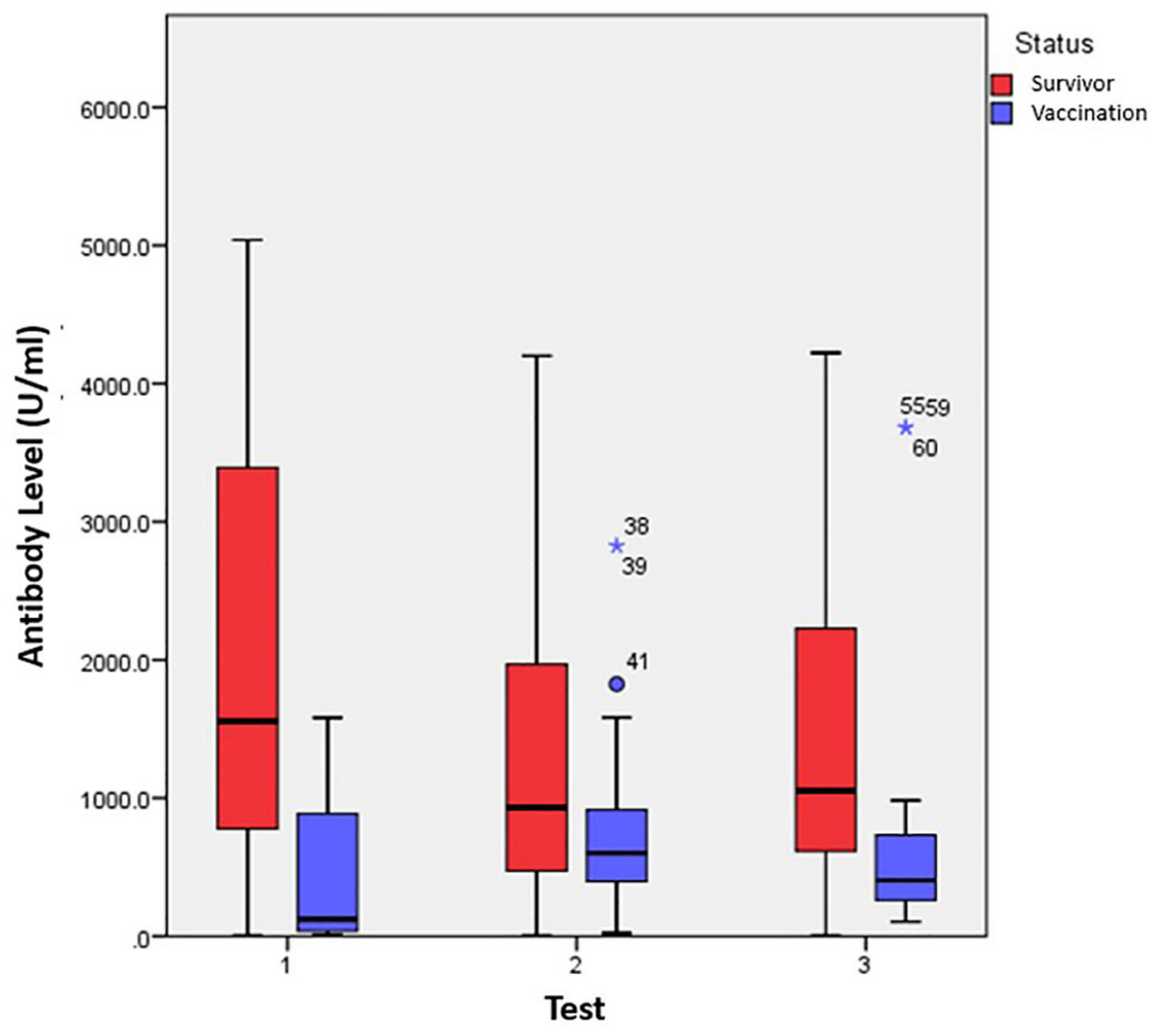

Figure 4. Distribution of antibody yield values based on vaccination status.

Table 6. Distribution of antibody levels in the total group according to the vaccination status.

\begin{tabular}{|l|l|l|l|l|}
\hline Test & Status & $\mathbf{n}$ & Mean Mann-Whitney U rank & p-value \\
\hline \multirow{2}{*}{ Test 1} & Survivor & 28 & 37.3 & 0.00 \\
\cline { 2 - 5 } & Vaccinated & 28 & 19.6 & 0.13 \\
\hline \multirow{2}{*}{ Test 2 } & Survivor & 28 & 31.7 & 0.01 \\
\cline { 2 - 5 } & Vaccinated & 28 & 25.2 & \\
\hline \multirow{2}{*}{ Test 3 } & Survivor & 28 & 34.3 & 22.5 \\
\cline { 2 - 5 } & Vaccinated & 28 & 28 & \\
\hline
\end{tabular}

dominated compared to the elderly group (62.5\% versus $37.5 \%$ ). This is in line with various reports of COVID-19 infection being more widely found in adult to elderly groups (Van Jaarsveld, 2020). ${ }^{5}$ Based on cross-description data, the study found a relatively balanced comparison between elderly survivors and vaccinated patients. In contrast, the younger age group was dominated by survivors, with a proportion of $32.1 \%$.

The present study (Table 6) show that (The results of this study generally showed significant) differences in antibody titer levels in the elderly group of survivors and vaccinated individuals, especially for the first test. This difference then became insignificant at the time of the second and third tests. The elderly survivor group showed differences in antibody titers in all three measurements taken. The same pattern was also observed for the group of vaccinated elderly, who also showed differences in titer levels over all tests conducted.

The results of this study are in line with those obtained by Soytas et al., ${ }^{6}$ who found that antibody titers were higher in the age group over 80 years, compared to the younger group ( $\geq 18$ and $<60$ Years). In the study, efforts were made to compare the level of IgG antibodies in confirmed SARS-CoV-2 patients with RT-PCR. IgG antibody levels and the time 
Table 7. Friedman test analysis.

\begin{tabular}{|c|c|c|c|c|}
\hline Group & Chi-square & p-value & Pair comparison & p-value \\
\hline \multirow[t]{3}{*}{ Elderly survivor } & \multirow[t]{3}{*}{7.40} & \multirow[t]{3}{*}{0.02} & Test 1 - Test 2 & 0.07 \\
\hline & & & Test 1 - Test 3 & 0.04 \\
\hline & & & Test 2 - Test 3 & 1.00 \\
\hline \multirow[t]{3}{*}{ Vaccinated elderly } & \multirow[t]{3}{*}{9.45} & \multirow[t]{3}{*}{0.01} & Test 1 - Test 2 & 0.01 \\
\hline & & & Test 1 - Test 3 & 1.00 \\
\hline & & & Test 2 - Test 3 & 0.09 \\
\hline \multirow[t]{3}{*}{ Non-elderly without comorbid survivors } & \multirow[t]{3}{*}{6.22} & \multirow[t]{3}{*}{0.04} & Test 1 - Test 2 & 0.05 \\
\hline & & & Test 1 - Test 3 & 0.18 \\
\hline & & & Test 2 - Test 3 & 1.00 \\
\hline \multirow[t]{3}{*}{ Vaccinated non-elderly without comorbid } & \multirow[t]{3}{*}{9.56} & \multirow[t]{3}{*}{0.01} & Test 1 - Test 2 & 0.01 \\
\hline & & & Test 1 - Test 3 & 0.71 \\
\hline & & & Test 2 - Test 3 & 0.17 \\
\hline \multirow[t]{3}{*}{ Non-elderly with comorbid survivors } & \multirow[t]{3}{*}{8.67} & \multirow[t]{3}{*}{0.01} & Test 1 - Test 2 & 0.10 \\
\hline & & & Test 1 - Test 3 & 0.01 \\
\hline & & & Test 2 - Test 3 & 1.00 \\
\hline \multirow[t]{3}{*}{ Vaccinated non-elderly with comorbid disease } & \multirow[t]{3}{*}{2.00} & \multirow[t]{3}{*}{0.37} & Test 1 - Test 2 & \\
\hline & & & Test 1 - Test 3 & \\
\hline & & & Test 2 - Test 3 & \\
\hline \multirow[t]{3}{*}{ Total survivor } & \multirow[t]{3}{*}{21.50} & \multirow[t]{3}{*}{0.00} & Test 1 - Test 2 & 0.00 \\
\hline & & & Test 1 - Test 3 & 0.00 \\
\hline & & & Test 2 - Test 3 & 1.00 \\
\hline \multirow[t]{3}{*}{ Total vaccinated } & \multirow[t]{3}{*}{14.357} & \multirow[t]{3}{*}{0.00} & Test 1 - Test 2 & 0.00 \\
\hline & & & Test 1 - Test 3 & 1.00 \\
\hline & & & Test 2 - Test 3 & 0.01 \\
\hline
\end{tabular}

required between RT-PCR positive results and antibody levels were recorded. A total of 1,071 patients were divided into two groups, namely group $1<60$ years $(n=902)$ and group $2>60$ years $(n=169)$. SARS-CoV-2 IgG antibody titers were higher in group $2(\mathrm{p}=0.001)$. These high results appeared in the first three months after RT-PCR detection was positive. Antibody titers were compared by dividing group 2 into three groups by age range (60-69, 70-79 and 80 years); the results showed higher antibody titers in 80 -year-old patients $(\mathrm{p}=0.044)$. High levels of COVID-19-specific IgG antibodies may be associated with the severity of the disease. ${ }^{7}$

The study conducted by Yang et al. ${ }^{8}$ evaluated 31,426 blood samples for SARS-CoV-2 antibodies level, showing that IgG levels differed by age group. Data were collected from New York City hospitals from April 9 to August 31, 2020. Semi-stimulative levels of IgG were compared between 85 pediatric patients and 3,648 adult patients. Further analysis of SARS-CoV-2 antibody profiles was performed in serum from 126 patients aged one to 24 years. Of 31,426 antibody test results (19,797 [63.0\%] female patients), with 1,119 pediatric patients (average [youngest] age; 11.0 [5.3] years) and 30,232 adult patients (average [SD] age, 49.2 [17.1] years), seroprevalence in pediatric patient populations (197 [16.5\%; $95 \% \mathrm{CI}, 14.4 \%-18.7 \%])$ and adults (5,630 [18.6\%; 95\% CI, 18.2\%-19.1\%]) showed similar results. SARS-CoV-2 IgG levels showed a negative correlation with age in the pediatric population $\left(\mathrm{R}^{2}=0.45, \mathrm{p}<0.001\right)$ and a moderate but positive correlation with age in adults $(\mathrm{r}=0.24, \mathrm{p}<0.001)$. Patients aged 19 to 30 years showed the lowest IgG levels (e.g., ages 25-30 years versus 1-10 years: 99 [44-180])). ${ }^{4}$ Furthermore, studies conducted by Roltgen et al. showed that vaccinated study participants in all age groups ( $<40$ years, 40 to 60 years, $>60$ years) developed a strong IgG antibody response, although younger individuals yielded higher concentrations of Ig antibodies compared to subjects older than 60.4 years.

Regarding the elderly who had been vaccinated, Muller et al. conducted a cohort study with two age groups, namely with individuals under the age of 60 years and over the age of 80 years, to compare their antibody responses to the first and 
second doses of BNT162b2 COVID-2019 vaccination by BioNtech (Germany) and Pfizer (USA). Although most participants in both groups produced titers of specific IgG antibodies for the SARS-CoV-2 S protein, the titers were significantly lower in the elderly participants. Although elevated antibody levels after the second immunization were higher in the elderly participants, the average absolute titer level of this group remained lower than that in the $<60$ age group. After the second vaccination, $31.3 \%$ of the elderly (>80 years) had no detectable specific antibodies, compared to the younger group, in whom only $2.2 \%$ had no detectable specific antibodies. ${ }^{9}$

The effectiveness of vaccines in the elderly has not been widely studied until now. (Weinberger, 2018, Van Jaarsveld, 2020) Markers commonly used to assess immunization effectiveness are antibody titers, antibody isotypes, and the immune system's ability to neutralize pathogens. ${ }^{10}$ Immunosenescence is a term used to describe decreased immunity with age, encompassing quantitative and qualitative aspects of the immune system response that are likely to impact the safety and effectiveness of the observed vaccine. ${ }^{11}$ As we grow older, the number of naive $\mathrm{T}$ cells available to respond to vaccines decreases (Valiathan et al., 2016). The normal ratio of CD4:CD8 cells increases with age, and becomes much higher in older age, due to a significant decrease in CD8 T cells (McBride and Striker, 2017). Aging also leads to a loss of CD8 and CD4 T cells receptor diversity, and overall reduces T cell viability. Qualitative changes include a shift in lymphocyte production to short-lived effector T cells instead of memory progenitor cells, resulting in a disruption of the response of helper T cells to vaccination. ${ }^{11,12}$ The number of B cells tends to be constant with age, but reduced expression of certain proteins leads to fewer functional antibodies being produced (Montecino-Rodriguez, 2013). Therefore, theoretically, vaccines may tend to be less effective in the elderly. Furthermore, the relative importance of the cellular aspect of the immune response in COVD-19 is unclear, especially in the elderly, so antibody levels may not be sufficient to induce immunity (Hasan et al., 2021). The impact of immunosenescence on vaccine safety is also uncertain. ${ }^{13}$ Although the risk of serious side effects mediated by overactivation of the immune system is theoretically lower, the condition is also offset by an increased tendency to general side effects resulting from aging. ${ }^{14}$

In our study, there was a difference in antibody titers between the survivor and vaccinated groups in the young age subgroup with no comorbidities, for the first and third tests. The difference was not significant for the second test. In contrast, overall, in the young survivor age group without comorbidities, there was also a difference between titer levels for all three tests conducted. The same was also found in young age group without comorbidities undergoing vaccinations.

The Ritchie et al. ${ }^{15}$ study measured antibodies specific to the $\mathrm{S}$ protein from patients who had been diagnosed with COVID-19, between January 1 and June 30, 2020, using enzyme-linked immunosorbent assays during the acute and/or convalescent phase. A total of 84 individuals participated in the study. Of those, 19 participants had antibody titers measured during the recovery phase and 65 patients had antibody titers measured during the acute and recovery phases. In 65 patients with two antibody measurements, all had higher antibody titers during the recovery phase. Factors associated with increased antibody titers and subsequent development of antibody titers were evaluated. Significant effects were found for antibody titers and age $(\mathrm{p}=0.006)$, sex $(\mathrm{p}=0.06)$, hypertension $(\mathrm{p}=0.07)$, diabetes mellitus $(\mathrm{DM})(\mathrm{p}=0.02)$, hyperlipidemia $(\mathrm{p}=0.009)$, smoking $(\mathrm{p}=0.02)$, lung disease $(\mathrm{p}=0.04)$, oxygen inhalation during hospitalization $(p=0.02)$, ventilation management $(p=0.06)$, use of glucocorticoids $(p=0.03)$, increase in temperature $(p=0.003)$, increase in maximum $\mathrm{C}$-reactive protein $(\mathrm{CRP})(\mathrm{p}<0.001)$, lactate dehydrogenase $(\mathrm{LDH})(\mathrm{p}<0.001)$, and fibrinogen levels $(p=0.01)$ during the course of the disease. Gradual multivariate analysis showed that male $\operatorname{sex}(p=0.04), D M$ $(\mathrm{p}=0.03)$, and maximum increase in CRP during the acute phase $(\mathrm{p}<0.001)$ were associated with increased IgG antibodies. Glucocorticoid use was not associated with antibody titers. ${ }^{15,16}$

Comorbid individuals are a high-risk group for COVID-19, but so far the effectiveness and safety profile of COVID-19 vaccination in that group has not yet been concluded on (Bellido and Peréz, 2021). The study, conducted by Choi et al., compared the effects of comorbid conditions on each vaccine undergoing phases 2 and 3 of clinical trials. ${ }^{15}$ In phase 2 and 3 clinical trials, the Pfizer COVID-19 vaccine showed that the most commonly found comorbid conditions were hypertension $(24.5 \%)$, DM $(7.8 \%)$, and chronic lung disease $(7.8 \%)$. No significant differences in side effects were found in the comorbid group compared to the total sample population. Six deaths were reported: two in the vaccination group and four in the control group. Of the deaths in the vaccination group, one patient was obese and atherosclerotic, and it was assessed that the deaths were not vaccine-related. ${ }^{17}$ In phase 2 and 3 clinical trials conducted in the UK and Brazil for the AstraZeneca COVID-19 vaccine (BNT162b2), 39.3\% of the sample population had one or more underlying diseases, including obesity with a BMI of $30 \mathrm{~kg} / \mathrm{m}^{2}$, cardiovascular disease, lung disease, and DM. Although the preventive effect was slightly lower in patients with one or more underlying diseases (58.3\%; 95\% CI: 33.6-73.9) compared to the total sample population, the difference was not statistically significant. No deaths were found related to vaccinations. $^{17,18}$ 
In this study, there were no differences in antibody titers between young survivor age groups who had comorbidities compared to those who underwent vaccination. After further analysis, a difference in titers was found between the three tests in the young survivor age group with comorbidities. However, there was no significant difference in antibody titers between the three tests in the young age group with comorbidities who received vaccinations. This difference between the vaccination and survivor groups possibly occurred due to the decrease in the median antibody titers in the survivor group, along with an increase in the median value in the vaccination group.

Overall, in all subjects indiscriminate of their age group, it was seen that there were differences in antibody titers in the survivor and vaccination groups. There was also a decrease in the median value in the survivor group and an increase in the median value of antibody titers in the vaccinated group. During further analysis, titers for both survivor and vaccinated groups also showed differences between the three tests performed. Zhou et al. ${ }^{19}$ conducted a seroconversion study in 173 patients affected by COVID-19, using tests developed to detect antibodies to the S protein RBD of SARS-CoV-2. ${ }^{11}$ The median seroconversion time of total antibody seroconversion, $\operatorname{IgM}$, and $\operatorname{IgG}$ was 11, 12, and 14 days respectively. Seroconversion rates for total antibodies, IgM, and IgG were $93.1 \%, 82.7 \%$, and $64.7 \%$, respectively, with cumulative seroconversion curves indicating that total antibody levels and IgM reached $100 \% 30$ days after onset. ${ }^{18,20}$ Antibody sensitivity goes beyond the RNA test from day 8 after the onset of symptoms and reaches more than $90 \%$ on the $12^{\text {th }}$ day after onset. ${ }^{18}$ Among samples from advanced-phase patients (days 15-39 after onset), sensitivity to total antibodies, IgM, and IgG was $100.0 \%, 94.3 \%$, and $79.8 \%$ respectively. In contrast, RNA was only detected in $45.5 \%$ of samples from day 15-39. ${ }^{18}$ Analysis of 285 patients further supported IgG seroconversion within 19 days after the onset of symptoms. ${ }^{19,21}$

\section{Conclusions}

Based on demographic data, female patients accounted for the majority at 60.7\%. Most of the participants belonged to the non-elderly age group, which was further divided into two more groups, i.e., those living with a comorbidity and those with no comorbidity, with the same number of samples as elderly respondents. The proportion between the group of survivors and vaccinations for both the elderly and nonelderly categories were balanced. Antibody titers in the elderly group of survivors relatively decreased with time. The antibody titer in the elderly group undergoing vaccination relatively increased. Antibody titers in the elderly survivor group and those who underwent vaccination were significantly different for the first test. Antibody titers in non-elderly survivor groups without comorbidities relatively decreased. Antibody titers in nonelderly groups without comorbidities undergoing vaccination were relatively elevated. Antibody titers in non-elderly without comorbidities in both unvaccinated and vaccinated groups were significantly different for the first and third tests. Antibody titers in non-elderly groups with comorbidities in survivors decreased. Antibody titers in nonelderly groups with comorbidities undergoing vaccination relatively decreased. No significant difference in antibody titers was detected between non-elderly survivors with comorbidities and vaccinated non-elderly with comorbidities. In the survivor group, a decrease in antibody levels was found, especially at 56 days and 84 days after COVID-19 diagnosis. In the group undergoing vaccination an increase in antibody levels was shown, especially at 56 and 84 days after the first vaccination. In this study, a significant difference in antibody titers in the first and third tests was found between a group of recovering COVID-19 cases and participants who underwent vaccination. In the entire group, there were significant differences between the three tests conducted, except in nonelderly groups with comorbidities. From this study, it was found that in the survivor group, antibody titers were still found for 84 days after a COVID-19 diagnosis. In the vaccinated group, it was found that antibody titers increased significantly at 56 days after vaccination.

\section{Data availability}

Underlying data

Figshare: Comparison of Immunogenicity Response Between Natural COVID-19 and Post-Vaccination Infections. https://doi.org/10.6084/m9.figshare.16995010.v122

This project contains the following underlying data:

- Raw Data for Comparison of Immunogenicity Response Between Natural COVID-19 and Post-Vaccination Infections.

Data are available under the terms of the Creative Commons Zero "No rights reserved" data waiver (CC0 1.0 Public domain dedication). 
1. Pal M, Berhanu G, Desalegn C, et al.: Severe Acute Respiratory Syndrome Coronavirus-2 (SARS-CoV-2): An Update. Cureus. 2020; 12(3): e7423. Published 2020 Mar 26. PubMed Abstract | Publisher Full Text

2. Dinleyici EC, Borrow R, Safadi MAP, et al.: Vaccines and routine immunization strategies during the COVID-19 pandemic. Hum Vaccin Immunother. 2021; 17(2): 400-407. PubMed Abstract | Publisher Full Text

3. Pascual-Iglesias A, Canton J, Ortega-Prieto AM, et al.: An Overview of Vaccines against SARS-CoV-2 in the COVID-19 Pandemic Era. Pathogens. 2021; 10(8): 1030. Published 2021 Aug 14. PubMed Abstract | Publisher Full Text

4. Wu Z, Hu Y, Xu M, et al.: Safety, tolerability, and immunogenicity of an inactivated SARS-CoV-2 vaccine (CoronaVac) in healthy adults aged 60 years and older: a randomised, double-blind, placebo-controlled, phase 1/2 clinical trial. Lancet Infect Dis. 2021 Jun; 21(6): 803-812.

Publisher Full Text | PubMed Abstract | Free Full Text

5. Martins Van Jaarsveld G. The Effects of COVID-19 Among the Elderly Population: A Case for Closing the Digital Divide. Front Psychiatry. 2020 Nov 12; 11: 577427. Publisher Full Text | PubMed Abstract | Free Full Text

6. Soytas BR, Cengiz M, Islamoglu MS, et al.: Does the CovID-19 seroconversion in older adults resemble the young?.J Med Virol. 2021 Oct; 93(10): 5777-5782.

Publisher Full Text | PubMed Abstract

7. Schoeman D, Fielding BC: Coronavirus envelope protein: current knowledge. Virol J. 2019 May 27; 16(1): 69,

Publisher Full Text | PubMed Abstract

8. Yang HS, Costa V, Racine-Brzostek SE, et al.: Association of Age With SARS-CoV-2 Antibody Response. JAMA Network Open. 2021 Mar 22; 4(3): e214302,

Publisher Full Text | PubMed Abstract

9. Müller L, Andrée M, Moskorz W, et al. : Age-dependent Immune Response to the Biontech/Pfizer BNT162b2 Coronavirus Disease 2019 Vaccination. Clin Infect Dis. 2021 Apr 27 [cited 2021 Sep 26]; 73: 2065-2072.

Publisher Full Text | PubMed Abstract

10. World Health Organization: Weeklly epidemiological update on COVID-19. 13 July 2021. Indonesia: World Health Organization; 2021 Jul; p.1-16. Report No.: 48.
11. World Health Organization: COVID-19 Indonesia situation report World Health Organization; 2021 Jul; p. 1-37. Report No.: 63.

12. Park JW, Lagniton PNP, Liu Y, et al.: mRNA vaccines for COVID-19: what, why and how. Int J Biol Sci. 2021 Apr 10; 17(6): 1446-1460. Publisher Full Text | PubMed Abstract

13. Soiza RL, Scicluna C, Thomson EC: Efficacy and safety of COVID-19 vaccines in older people. Age Ageing 2020 Dec 50; 50: 279-283. Publisher Full Text

14. The pandemic pipeline - PubMed: [cited 2021 Jul 20]. PubMed Abstract

15. Ritchie $H$, Ortiz-Ospina E, Beltekian D, et al.: Coronavirus Pandemic (COVID-19). Our World in Data. 2020 Mar 5 [cited 2021 Jul 20]. Reference Source

16. Kutsuna $S$, Asai $Y$, Matsunaga A, et al.: Factors associated with antiSARS-CoV-2 IgG antibody production in patients convalescing from COVID-19. J Infect Chemother. 2021 Jun 1; 27(6): 808-813. Publisher Full Text | PubMed Abstract

17. Halim M: COVID-19 Vaccination Efficacy and Safety Literature Review. J Clin Med Res. 2021 Feb 2. Publisher Full Text

18. Mahanty S, Prigent A, Garraud O: Immunogenicity of infectious pathogens and vaccine antigens. BMC Immunol. 2015 May 29; 16 31. Publisher Full Text | PubMed Abstract

19. Zhou F, Yu T, Du R, et al.: Clinical course and risk factors for mortality of adult inpatients with COVID-19 in Wuhan, China: a retrospective cohort study. The Lancet. 2020 Mar; 395(10229): 1054-1062. Publisher Full Text | PubMed Abstract

20. Janeway's Immunobiology - Kenneth Murphy, Casey Weaver Google Buku. [cited 2021 Jul 20]. Reference Source

21. Ritchie $\mathrm{H}$, Ortiz-Ospina E, Beltekian D, et al.: Coronavirus Pandemic (COVID-19). Our World in Data. 2020 Mar 5 [cited 2021 Jul 20]. Reference Source

22. Kristanto E: Raw Data For Comparison of Immunogenicity Response Between Natural COVID-19 and Post-Vaccination Infections. figshare. Dataset. 2021.

Publisher Full Text 


\section{Open Peer Review}

\section{Current Peer Review Status:}

\section{Version 1}

Reviewer Report 08 March 2022

https://doi.org/10.5256/f1000research.79420.r124630

(C) 2022 Sensusiati A. This is an open access peer review report distributed under the terms of the Creative Commons Attribution License, which permits unrestricted use, distribution, and reproduction in any medium, provided the original work is properly cited.

\section{Anggraini Dwi Sensusiati}

Department of Radiology, Universitas Airlangga Hospital, Surabaya, Indonesia

This is good research and it is needed to make people sure that vaccination is very important. Some comments:

1. The method of this study is clearly reported, but the decision of 30 subjects must be explained.

2. The references must be added to make the background more comprehensive.

3. Comorbidity in this research must be explained before the results.

4. "No significant difference in antibody titers was detected between non-elderly survivors with comorbidities and vaccinated non-elderly with comorbidities" this needs more explanation in the discussion based on references.

5. A short and clear conclusion will be better.

Is the work clearly and accurately presented and does it cite the current literature? Yes

Is the study design appropriate and is the work technically sound? Partly

Are sufficient details of methods and analysis provided to allow replication by others? Yes

If applicable, is the statistical analysis and its interpretation appropriate? Yes

Are all the source data underlying the results available to ensure full reproducibility? 
Yes

Are the conclusions drawn adequately supported by the results?

Yes

Competing Interests: No competing interests were disclosed.

Reviewer Expertise: COVID-19 Research and Radiology

I confirm that I have read this submission and believe that I have an appropriate level of expertise to confirm that it is of an acceptable scientific standard.

\section{Comments on this article}

\section{Version 1}

Reader Comment 23 Feb 2022

Andika Surya, Neurologi, Indonesia, Indonesia

Nice article!!

thankyou..

Competing Interests: No competing interests were disclosed.

The benefits of publishing with F1000Research:

- Your article is published within days, with no editorial bias

- You can publish traditional articles, null/negative results, case reports, data notes and more

- The peer review process is transparent and collaborative

- Your article is indexed in PubMed after passing peer review

- Dedicated customer support at every stage

For pre-submission enquiries, contact research@f1000.com

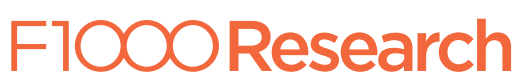

